\title{
Physicians' perspectives on receiving unsolicited genomic results
}

\author{
Douglas B. Pet, MD ${ }^{1}$, Ingrid A. Holm, MD, MPH ${ }^{2,3}$, Janet L. Williams, MS, LGC ${ }^{4}$, \\ Melanie F. Myers, $\mathrm{PhD}^{5,6}$, Laurie L. Novak, PhD, MHSA${ }^{7}$, Kyle B. Brothers, MD, PhD ${ }^{8}$, \\ Georgia L. Wiesner, MD, MS ${ }^{7,9}$ and Ellen W. Clayton, MD, JD
}

Purpose: Physicians increasingly receive genomic test results they did not order, which we term "unsolicited genomic results" (UGRs). We asked physicians how they think such results will affect them and their patients.

Methods: Semistructured interviews were conducted with adult and pediatric primary care and subspecialty physicians at four sites affiliated with a large-scale return-of-results project led by the Electronic Medical Records and Genomics (eMERGE) Network. Twenty-five physicians addressed UGRs and (1) perceived need for actionability, (2) impact on patients, (3) health care workflow, (4) return of results process, and (5) responsibility for results.

Results: Physicians prioritize actionability of UGRs and the need for clear, evidence-based "paths" for action coupled with clinical decision support (CDS). They identified potential harms to patients including anxiety, false reassurance, and clinical disutility.
Clinicians worried about anticipated workflow issues including responding to UGRs and unreimbursed time. They disagreed about who was responsible for responding to UGRs.

Conclusion: The prospect of receiving UGRs for otherwise healthy patients raises important concerns for physicians. Their responses informed development of an in-depth survey for physicians following return of UGRs. Strategic workflow integration of UGRs will likely be necessary to empower physicians to serve their patients effectively.

Genetics in Medicine (2019) 21:311-318; https://doi.org/10.1038/s41436018-0047-z

Keywords: Return of research results; Unsolicited genomic results; Physicians; Attitudes; Ethics

\section{INTRODUCTION}

Healthy individuals are increasingly receiving results from genomic testing that indicate disease risk. Testing frequently occurs without medical indication and often outside the clinic in the setting of research studies ${ }^{1,2}$ or direct-to-consumer services. ${ }^{3,4}$ Positive results may be unexpected, particularly if there are no corresponding symptoms or family history. Concerned recipients may turn to their physicians who typically are not geneticists to interpret results that these clinicians did not order. ${ }^{5}$ We characterize these results from the clinician's perspective as "unsolicited genomic results" (UGRs) because these tests were initiated outside the clinical setting. The fact that these results originate outside the clinical setting distinguishes them from tests ordered by a treating clinician who then becomes responsible for following up on findings pertinent to the clinical question as well as any secondary findings.

Although many patients want advice about how to understand and act on UGRs ${ }^{6,7}$ and clinicians may be approached to provide this assistance, ${ }^{8}$ not enough is known about what nongeneticist clinicians think about circumstances under which genomic results should be returned to patients. ${ }^{9,10}$ Data are only now emerging about how these clinicians plan to address unsolicited results in their practices. ${ }^{11}$ Previous studies have reported that nongeneticist health care providers (HCPs) often are uncomfortable with prospective genomic information ${ }^{12}$ and do not agree about who is responsible for responding to it in the clinical setting. ${ }^{13,14}$

UGRs may present professional challenges to HCPs who are expected to translate "actionable" results into clinical practice. Understanding clinicians' concerns in this area would help to provide a more complete picture of how genomic screening may play out in the context of real-time health care delivery. HCPs involved in direct patient care can alert us to technical roadblocks or ethical pitfalls, which may be less apparent at the level of research design. These perspectives therefore warrant the attention of researchers and others advocating translational projects so that the benefits of clinical genomics can be realized and harms can be anticipated and avoided. ${ }^{15}$

The Electronic Medical Records and Genomics (eMERGE) Network, a national research consortium focused on combining genomics and electronic health records (EHRs) for

\footnotetext{
${ }^{1}$ Vanderbilt University School of Medicine, Nashville, Tennessee, USA; ${ }^{2}$ Boston Children's Hospital, Boston, Massachusetts, USA; ${ }^{3}$ Harvard Medical School, Boston, Massachusetts, USA; ${ }^{4}$ Geisinger, Danville, Pennsylvania, USA; ${ }^{5}$ Cincinnati Children's Hospital Medical Center, Cincinnati, Ohio, USA; ${ }^{6}$ University of Cincinnati, College of Medicine, Cincinnati, Ohio, USA; ${ }^{7}$ Vanderbilt University Medical Center, Nashville, Tennessee, USA; ${ }^{8}$ University of Louisville School of Medicine, Louisville, Kentucky, USA; ${ }^{9}$ Vanderbilt-Ingram Cancer Center, Nashville, Tennessee, USA; ${ }^{10}$ Vanderbilt University School of Law, Nashville, Tennessee, USA. Correspondence: Ellen W. Clayton (ellen.clayton@vanderbilt.edu)
} 
discovery and patient care, is an ideal setting in which to study these issues. ${ }^{16}$ In eMERGE III, over 20,000 consented participants across the 10 clinical sites, most of whom are healthy and lack a medical indication for genomic testing, are undergoing sequencing of a panel of approximately 110 "actionable" genes linked to treatable and/or preventable diseases. The gene panel includes the American College of Medical Genetics and Genomics' list of 59 reportable secondary findings, ${ }^{1}$ while the remaining tested genes vary by eMERGE III site. Positive results are being returned to participants and their physicians and placed in the EHR. For most HCPs, these will be UGRs as the HCP did not order the panel and often did not know that the genomic testing was being performed.

One of the goals of eMERGE III is to study how receiving genomic results affects HCPs and clinical practice. We are conducting a study across the ten eMERGE sites to understand more fully what physicians find important regarding UGRs and how they may respond to receiving such results in a real-world setting. As a first step, we interviewed primary care providers and nongeneticist specialists several months before any eMERGE III results were returned to identify their perspectives on actionability of and responsibility for UGRs, impact on patients and workflow, and support needs. Mapping how physicians think about UGRs has also informed the development of a survey to capture HCPs' experiences after eMERGE III results are returned.

\section{MATERIALS AND METHODS}

Members of the eMERGE III HCP Work Group recruited physicians from three eMERGE III sites: Vanderbilt Medical Center, Nashville, TN; Geisinger, Danville, PA; and Cincinnati Children's Hospital Medical Center (CCHMC), Cincinnati, $\mathrm{OH}$. Physicians were also recruited from an eMERGE affiliate site at the University of Louisville (UL), Louisville, KY. Respondents were experienced and highly regarded practitioners who actively practiced adult and/or pediatric primary care, oncology, or cardiology. Clinicians directly involved with eMERGE or other major genomics projects were excluded. Participants at Geisinger, UL, and CCHMC received a \$50 incentive. Following institutional review board (IRB) approval at all four sites, four Work Group members conducted semistructured interviews following verbal informed consent using an interview guide developed primarily by D.P. (Supplemental Item A). Interviews, which were pretested, included hypothetical patient scenarios involving UGRs that would be returned in eMERGE III. These scenarios were developed through iterative discussion among Work Group members and served as a spur to broader discussion. These scenarios were followed by questions that probed physicians' opinions about forthcoming eMERGE III results and UGRs in general across five general domains: (1) actionability, (2) impact on patients, (3) health care workflow, (4) return of results process and support, and (5) responsibility for results. Interviews were audio-recorded, transcribed, and then coded using the Dedoose (http://www.dedoose.com) cloud-based qualitative analysis platform.
Codes were analyzed using a framework approach, ${ }^{17}$ a technique involving the incorporation of pre-established thematic domains. Consensus on the coding framework was reached as follows: D.P. coded five transcripts, starting with five deductive parent codes corresponding to interview domains. Subcodes were added inductively as subthemes arose from the transcripts. Blinded to D.P.'s code applications, E.W.C. applied the developing codebook to two of the five transcripts, adding new subcodes at her discretion. L.N. mediated review and discussion of discrepant code definitions and applications and resolved areas of disagreement. The codebook was updated, reviewed by Work Group members, and finalized through iterative feedback and discussion. Remaining transcripts were coded by D.P. Blinded coding of three later transcripts by D.P and E.W.C. demonstrated "substantial"18 interrater agreement (Cohen's Kappa 0.74).

\section{RESULTS}

We recruited 25 physicians specializing in pediatric or adult primary care, cardiology, or oncology. Ten primarily cared for adult patients, 14 for pediatric patients, and 1 for both (Table 1). Interview data were coded within the five original thematic domains and subcoded within more granular subthemes (Table 2). A sixth domain was added to capture general attitudes about returning UGRs to patients and providers (Supplemental Item B). We reached thematic saturation after approximately 15 interviews. Data collection continued to diversify input across site and medical specialty.

\section{Actionability}

Physicians almost always stated that only actionable genomic results should be returned to patients and providers. Participants outlined several factors, positive and negative, affecting their perception that UGRs needed to be actionable (Supplemental Item C). They defined actionability in practical terms, emphasizing the need for a "clear path" forward and established "standard[s] of practice" associated with each potential result. Actionability hinged on dictating concrete steps that could significantly change patients' disease courses, improve quality of life, or, as one interviewee stated, "reduce their risk of death or disability" (adult primary care provider [PCP] 19). Respondents condemned the idea of returning UGRs based on theoretical benefit: "...we are not just finding this out because oh it's interesting, but it's actually going to affect their clinical care" (pediatric oncologist 01).

Physicians used the language of evidence-based medicine, citing the need for supporting data on penetrance, test performance (false positive/negative rates), predictive value, and patient outcomes. Many asserted that actions taken based on positive results, as well as the decisions about whether to test in the first place, should be subject to the same evidentiary requirements as other medical screenings and interventions. Many expressed significant doubts that returning and acting upon eMERGE III results would meet this standard: 
Table 1 Participant demographics

\begin{tabular}{|c|c|c|}
\hline & $N$ & $\%$ \\
\hline Total interviewed & 25 & 100 \\
\hline \multicolumn{3}{|l|}{ Interview site } \\
\hline Vanderbilt University Medical Center & 7 & 28 \\
\hline Cincinnati Children's Hospital Medical Center & 6 & 24 \\
\hline Geisinger & 5 & 20 \\
\hline University of Louisville Hospital & 7 & 28 \\
\hline \multicolumn{3}{|l|}{ Sex } \\
\hline Female & 14 & 56 \\
\hline Male & 11 & 44 \\
\hline \multicolumn{3}{|l|}{ Ethnic/racial background } \\
\hline White & 19 & 76 \\
\hline Black/African American & 3 & 12 \\
\hline Asian & 3 & 12 \\
\hline \multicolumn{3}{|l|}{ Patient population } \\
\hline Adult only & 10 & 40 \\
\hline Pediatric only & 14 & 56 \\
\hline Adult and pediatric & 1 & 4 \\
\hline \multicolumn{3}{|l|}{ Clinical specialty } \\
\hline Primary care provider & 13 & 52 \\
\hline Oncologist & 6 & 24 \\
\hline Cardiologist & 6 & 24 \\
\hline \multicolumn{3}{|l|}{ Year in practice (since end of residency) } \\
\hline $1-5$ & 6 & 24 \\
\hline $6-9$ & 2 & 8 \\
\hline $10-14$ & 5 & 20 \\
\hline$>15$ & 12 & 48 \\
\hline \multicolumn{3}{|c|}{$\begin{array}{l}\text { Level of comfort responding to patients' questions about genetics/ } \\
\text { genomics }\end{array}$} \\
\hline Not comfortable & 6 & 24 \\
\hline Somewhat comfortable & 13 & 52 \\
\hline Comfortable & 4 & 16 \\
\hline Confident & 2 & 8 \\
\hline
\end{tabular}

"I believe that my job is to recommend things to my patients that are backed up by evidence-based medicine. So if I can't tell my patient that this genetic testing is evidencebased, I cannot, in all good faith, as your physician, recommend it to you. Just like...I don't strongly recommend PSA testing. I don't strongly recommend mammograms between age 40 and 50 . Now, if you've got a good reason why you want to go get a mammogram between age 40 and 50, because you are anxious, you can't sleep at night, you have this friend who got breast cancer at age 42 and it freaks you out, then you as an individual, I'm going to say, okay, let's talk about you as an individual and whether or not you need to go get that...but as a general sense, I can't recommend unsolicited genetic screening because I don't think there's enough evidence behind it." (adult PCP 20)

Others seemed more comfortable with returning UGRs despite limited supporting data:
“The problem with some of these is we don't know if screening-like if we have a new genetic abnormality, do we know if...a change in the screening actually improves outcomes for those people or not? So now we're dealing with something we don't really have evidence for, which we do a lot in this and I don't really mind that necessarily." (adult PCP 16)

Many physicians were concerned that they would not know how to respond to UGR, which necessarily would limit the actionability of a given result. One interviewee stated, "I feel completely unprepared to do it" (adult PCP 16). Some also expressed doubts that relevant subspecialists would know how to respond to a positive UGR if the patient was not already symptomatic.

\section{Impact on patients}

Physicians identified potential benefits of UGRs including targeted screening, earlier interventions, and establishment of care with appropriate specialists. Some believed that UGRs could enhance routine care, with one respondent adding that a person's results, "may explain [symptoms] that they didn't understand or their doctor didn't understand or missed" (adult PCP 21). Others noted that results may be useful to family members or alert children about potential health concerns. Some thought about the benefits of uncovering risk of sudden-onset and/or deadly conditions. "...finding that somebody has long QT syndrome and could potentially drop dead and might live a long life with a pacemaker is a very easy one that I have no ethical issues with screening people who are asymptomatic" (pediatric oncologist 01).

Interviewees spoke in greater depth about the potential harms associated with returning UGRs to the general population. Inducing patient anxiety was a prominent and widely voiced concern. Physicians worried that little could be done to offset psychological distress about diseases that patients may or may not develop.

"You have a genetic, like a genotypically positive thing with presumably a phenotypically negative patient... and now it's their dilemma, like you pass it on to the patient. Or share it now with the patient. And so, I think they would naturally assume a lot of that anxiety or uncertainty. And for laypeople, I think that's a very heavy burden to bear." (pediatric cardiologist 17)

Some opined that, for many patients, positive genomic findings could equate to "diagnoses"-a scenario, which in one participant's view, "can turn someone who is not sick in to a patient so to speak" (pediatric cardiologist 05). Many shared a related concern that negative results could be falsely reassuring. One pediatrician alluded to potential implications for parent-child relationships:

"We may be creating a lot of disease here where there isn't any. So, that's the down side of this too. Parents who have 
Table 2 Themes reflected in physicians' perspectives on unsolicited genomic results (UGRs)

\begin{tabular}{ll} 
Domains & Key themes \\
\hline Actionability & Physicians expect results to be \\
actionable \\
Informing disease prevention, \\
screening, and/or management \\
actions \\
Importance of data/evidence-based \\
process, or standard of practice
\end{tabular}

Impact on patients Enhanced screening and care
Anxiety/regret
and clinical disutility

Patients may become less insurable/ genetic discrimination

Consent issues regarding long-term impacts

Benefits to family members

False reassurance of health

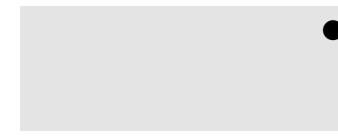

Health care

- Time burden/previsit preparation

workflow

Unreimbursed physician time

Insurance may not pay

Impression that work is being unfairly imposed

Physician liability

\section{Return of results} process and support

Physicians expect clinical decision support

- Need for interpretation, an action plan, and guidance on referrals - Direct access to consultants and specialists

\section{Representative comments}

"I wouldn't be delighted to get results on someone who needed counseling about something that we couldn't do anything about" (adult PCP 19)

"I wouldn't want all my patients having 100 tests done that I have to talk to them about and none of which have been proven to be good screening tests" (adult PCP 21)

"They shouldn't be testing them if they don't...have strong data to support us surveilling them differently" (adult PCP 19)

"... as long as there was some understanding of standard of practice... If I felt like I'm as up to date as I can possibly be on what others are doing with these" (pediatric cardiologist 17)

"As we get more and more of these and we start to develop these specialized clinics, like the high-risk breast clinic or the Lynch syndrome clinic, I think those are valuable resources" (adult oncologist 10)

"This is just going to make them a little bit more sad, a little bit more anxious, a little bit more frustrated... feeling like there's this ominous shadow that's waiting ahead of them and not much that we can do for it" (adult/pediatric PCP 09)

"There's the side effect of the next study which would be perfing someone's colon who didn't need a colonoscopy when their test was positive. Or heart catheterization when your calcium score or your genetic heart risk score was high" (adult PCP 22)

"The military won't accept people who have certain heart conditions and so what if you are at risk for that heart condition? ... You don't know how that information could get out if it's part of their record and how it could affect things like job prospects, insurance, and stuff" (pediatric cardiologist 05)

"It's hard to imagine that a person that's 8 years old, or 5 years old or even 14 years old can... really understand what getting those results may mean for them long term" (pediatric cardiologist 06)

"The real benefit of it is if we can get family members...treated or managed appropriately, too...it allows us to capture more people" (adult oncologist 10) "I think that the danger would be that patients would say, 'oh, everything's cool, I don't have anything.' Yet we're not at the point where we can really say that" (adult PCP 08)

"Because it's unsolicited, it would add a lot of kind of work, whether it's phone calls or counseling or added time to our visits" (pediatric cardiologist 17)

"If there are no RVUs associated, that's going to get you in trouble with your boss, that you spent that extra time discussing this" (pediatric cardiologist 25)

"You show up with a cough, if I can bill [insurance] for that... but if you show up with an ACTA2 variant, no, and if I order an echocardiograph, I don't know how they're going to pay for that" (adult PCP 23)

"Just adds another burden to the general pediatrician and I think it's not fair" (pediatric PCP 12)

"We may find in 15 years that that results in $90 \%$ risk of $X$ condition, but we don't know yet, well are we going to somehow be liable because we didn't tell them?" (pediatric oncologist 24)

"I need someone to educate me on the front end, I need reimbursed time to sit with the patient, and then I need educated people on the back end to follow-up with the patient" (adult PCP 20)

"A script...this is the way to speak about these results...this is what this could mean, this is what it's related to, and this is what to do next" (pediatric cardiologist 15)

"...not just like websites and stuff, but actually people you could talk to about if you wanted to do a face to face counseling or evaluation session" (pediatric cardiologist 17) 
Table 2 (continued)

\begin{tabular}{|c|c|c|}
\hline Domains & Key themes & Representative comments \\
\hline \multirow[t]{5}{*}{$\begin{array}{l}\text { Responsibility for } \\
\text { results }\end{array}$} & $\begin{array}{l}\text { Whoever orders the test is } \\
\text { responsible }\end{array}$ & $\begin{array}{l}\text { "... if they're saying this is important to know, that these are actionable, potentially } \\
\text { actionable items, then, and they're doing the tests, seems like this is their obligation to } \\
\text { tell the patient what it means" (adult PCP 21) }\end{array}$ \\
\hline & - Unclear who is responsible & $\begin{array}{l}\text { "...there maybe a little bit of trouble like who's, where's the ownership and I don't } \\
\text { know how that might work" (pediatric oncologist 01) }\end{array}$ \\
\hline & $\begin{array}{l}\text { Physician feels personally } \\
\text { responsible }\end{array}$ & $\begin{array}{l}\text { "The problem is I feel like once that information is on my desk or in my, once I've seen } \\
\text { it, I kind of feel like it's my responsibility to follow it up" (adult PCP 20) }\end{array}$ \\
\hline & $\begin{array}{l}\text { - Genetic specialist/ counselor } \\
\text { responsibility }\end{array}$ & $\begin{array}{l}\text { "The parents are going to want to know... what does this mean for the rest of my } \\
\text { family?...genetic counselors, that's what they do, so they should have that } \\
\text { responsibility, not me" (pediatric PCP 12) }\end{array}$ \\
\hline & $\begin{array}{l}\text { - Physician issues regarding } \\
\text { responding to tests they did not order }\end{array}$ & $\begin{array}{l}\text { "Having to give the information initially would upset me because I didn't order this" } \\
\text { (pediatric PCP 12) }\end{array}$ \\
\hline
\end{tabular}

$P C P$ primary care provider

[a result] that is a potential disease in the future and not even a definite disease in the future, may see that child differently, treat them differently. They never really understand that you said, 'but it's okay." (pediatric cardiologist 25)

Physicians worried that UGRs could lead to unnecessary interventions and concomitant risks, complications, and costs.

"'You told me I had this cardiomyopathy gene; I've never developed cardiomyopathy but I owe $\$ 5000$ in deductible each year because I was recommended to get an MRI and then when I got the MRI my IV infiltrated and I had a bad infection'...So the fact that it could lead to interventions or therapies or things that themselves have consequences." (pediatric cardiologist 05)

Subjects shared considerable concern about discrimination based on genomic risk information. Many thought patients would become less insurable.

"Now you have information that labels you with a potential for a disease...Are you going to have to pay more because you've been tested for this and you have a gene that says you might get something in 20 years?" (pediatric cardiologist 25)

Some doubted that patients could appropriately consent to broad, prospective genomic testing because the scientific and social implications are not sufficiently understood. Physicians also cited significant risk of patient regret after receiving results. Concerns about decision-making arose particularly with regard to minors, with one pediatric cardiologist questioning,

“...whether or not like a 7-year-old should know a result of a gene test that may or may not have any impact on their life the rest of their life, you know? And whether or not they should have their parents make those decisions for them." (pediatric cardiologist 06)

\section{Health care workflow}

Clinicians saw dealing with UGRs as a time burden, both in terms of added clinical tasks and pre-encounter preparation. Some thought that discussing UGRs would compete with other important tasks within a time-limited visit. PCPs were particularly averse to having work that they "didn't ask for" added to an already oversaturated schedule. "I would be angry if I received this [result], not having ordered these tests and being expected to deal with the results...primary care doctors, we get a lot of stuff dumped on us that we didn't order" (adult PCP 19). Others were less perturbed by the prospect of unsolicited results: "I didn't send it, but I will tell them... that happens already...it's kind of part of what we do" (pediatric cardiologist 25).

It was not clear to physicians if or how they would be reimbursed for professional time spent on UGRs. Many questioned whether insurance companies would pay to work up or intervene in response to positive UGRs and what that might mean for patients. "I doubt that insurance would pay...It's hard to find out. Will insurance pay for genetic counseling? I mean even if they will, how big is their deductible? Should patients have to pay for that?" (adult PCP 21).

Some interviewees feared that patient's genomic information would get lost or fail to be transferred with patients if they changed providers or health systems, especially if next steps are not made clear. "I think if you don't give them an explanation of what they do next, a lot of that stuff may fall through the cracks" (pediatric oncologist 24).

Respondents varied in their views of professional liability regarding UGRs. While some had few concerns, others expressed discomfort with disclosing, counseling, and setting expectations about positive UGRs. 
"If I was asked to share results for something that I don't normally follow or manage and how I presented it to the family could be seen as not complete or giving the wrong information. You know what I mean? 'Well you told us that yes you didn't order the test but you told us that it was diabetes and that can be managed and we went home and he had a, went into DKA and died'... What if I didn't stress the importance of it, what if I played it down, what if I didn't understand?" (pediatric cardiologist 05)

Physicians expected a low threshold for referring to other providers when faced with UGRs due to personal lack of expertise and a sense that specialists would be better suited to respond to results. One subject would immediately shift responsibility for care, noting, "if this came to me I would just send them. I wouldn't be involved in this" (pediatric cardiologist 06). Another provider noted that a lot of referrals are likely to result, some of which may be ill-informed: "I think it has the potential to generate a lot of subspecialty referrals from me as a primary care doctor without knowing if that is the right thing or the wrong thing to do" (adult PCP 20).

\section{Return of results process and support}

Physicians voiced significant expectations for well-developed clinical decision support (CDS) to be returned with UGRs: "I would like to have the information in front of me with a go-to plan and resources available to help...before I actually had a meeting with the patient" (adult PCP 19).

Some framed CDS as providing a clear set of instructions or scripts. "If I were to get this and it isn't in my specialty, I could look up an algorithm and say, oh, this is the variant. This is what it means. These are the screening paths, and these are who the people should see" (adult oncologist 10).

Respondents wanted CDS to include information on penetrance, prognosis, and urgency, as well as specific recommendations for screening, referrals, and the need for testing relatives. Several felt that CDS should include direct access, including phone numbers, to genetic experts, counselors, and/or eMERGE researchers spearheading the testing process. Many also said they would want to have materials designed specifically for patients and families. One clinician, however, was not content with being told what to do and instead noted the importance of being able to appraise available evidence critically: "I would love to see a systematic description of how well studied that correlation is, as well as a ranking of how strong that correlation is" (adult PCP 20).

\section{Responsibility for results}

Opinions varied about who should be responsible for dealing with UGRs returned through eMERGE III. Some providers felt that they should not be held responsible because prospective genomic testing fell outside of their scope of medical knowledge and practice. "I think these are really not approved screening tests so I don't think I would know what to do with these things" (adult PCP 21). Interviewees also asserted that certain responsibilities like counseling on implications for relatives and need for further genomic testing should reside with genetic specialists and/or counselors. Others would place responsibility for responding to results directly on ordering research personnel.

"I think if the eMERGE is going to release that information back to the family, they need to be responsible for interpreting and counseling those families about what it means. If not, you're passing the buck and they're frankly going to be better doing it than anybody else." (pediatric oncologist 24)

Not all endorsed this view, feeling that researcher responsibility would necessarily be limited to communicating results and need for follow-up: "...the problem is, is that the researcher is a researcher, they're not a clinician and they're not taking care of the patient as a patient, they're taking care of the patient as a research subject" (adult PCP 20). Thus, some physicians emphasized a need for a clear transfer of responsibility to a treating clinician. One oncologist noted, "I guess our biggest fear is with our cancer patients is them getting the information out of context and without their physician or their team being involved" (pediatric oncologist 02).

Physicians were often unclear on who should "own" the results of a patient, especially one seeing multiple specialists, or how this would be determined: “...you put [providers] in this situation where they may or may not know all the implications of what you're telling them, and what their duty is" (adult cardiologist 11). Nonetheless, some physicians said, once they know about a result, they feel personally obligated to respond regardless of who ordered the test. One PCP remarked that "[UGRs] would fall into that rather broad category of I would have to mess with it at least initially. You know, I own everything that everyone else owns. Or that anyone else won't claim" (adult PCP 23).

\section{DISCUSSION}

Many research participants, ${ }^{9,19}$ genomics researchers, ${ }^{20,21}$ and scholars in ethical, legal, and social implications of genomics ${ }^{22,23}$ have advocated for the return of individual results from genomics research. Research to explore the impact of return of individual results in translating genomic research to clinical care is being funded by the National Human Genome Research Institute $24-26$ and is a central element of the Precision Medicine Initiative. ${ }^{27}$ In addition, people in growing numbers seek health-related genetic information from directto-consumer companies. ${ }^{28}$ As a result, clinicians will increasingly be asked to advise patients about genomics results that were not ordered by treating physicians. Although geneticists and genetic counselors will provide some of this counseling, there are not enough of them to meet the potential need, and in many cases, they will not be the first clinicians these patients see. Thus, it is critical to understand the impact of UGRs on clinicians who do not have specialized training in genetics. 
In our study, nongeneticist physicians expressed numerous concerns about receiving UGRs for a general "healthy" population. Study participants viewed the eMERGE III project as a form of opportunistic medical screening ${ }^{29,30}$ and raised concerns that large panel-based risk testing lacked validation compared with familiar evidence-based screening practices. Receiving positive results was seen as problematic in the absence of evidence-based management guidelines dictating interventions proven to benefit patient health. These sentiments were in line with prior findings that physicians question the current clinical utility of genomic sequencing. ${ }^{31}$ At the same time, interviewees acknowledged that interventions and treatments are sometimes put into practice despite lacking the highest levels of medical evidence, noting, as have others, ${ }^{32}$ that genomics will be important in future health care and that growing pains are inevitable.

Actionability of results was highly important to physicians, and perceptions of actionability shaped attitudes toward UGRs. These physicians expected actionable results to dictate well-established care pathways that were not only based on transparent evidence but also clinically feasible and accessible to patients. Importantly, they wanted assurance that these requirements had been met. These expectations, however, may not always be realistic or possible in this era where the clinical management for genetic conditions is evolving as new information is generated. Further, from whose perspective actionability should be defined, and what it should include, is hotly debated, with many arguing that patients should have access to information about reproductive risk, findings they find personally meaningful, or raw sequence data. ${ }^{6,22}$ What is necessary to demonstrate the efficacy of interventions is also contested, ${ }^{33}$ especially because many of these disorders are uncommon.

Physicians were particularly concerned about scenarios in which a positive result was received for which little or nothing could be done. Despite evidence that most patients do not experience undue distress from receiving genomic results, ${ }^{34,35}$ clinicians feared this would leave patients anxious and physicians with much to answer for and little to offer. Interviewees further felt that positive UGRs would lead to unnecessary procedures and costs. ${ }^{36,37}$ They also raised social concerns related to placing UGRs in the EHR, including risks to privacy and future insurability, even though some of these risks should be ameliorated by the Genetic Information Nondiscrimination $\mathrm{Act}^{38}$ and the pre-existing condition provisions of the Affordable Care Act. ${ }^{39}$

Clinicians felt that dealing with UGRs could disrupt clinical workflow and would lead to inappropriate referrals and uncompensated professional time. Furthermore, it was largely unclear to physicians who would be responsible for the UGRs in both the short and long term. Some physicians worried about losing track of result information leading to unfulfilled obligations to patients and some risk of physician liability, concerns that are not entirely unfounded. ${ }^{40}$

Like others, ${ }^{12}$ we found that providers felt generally unprepared and undertrained to respond to UGRs. They articulated a high level of need and expectation for clinical decision support including access to consultants and materials for patients. Some physicians expressed resentment toward being expected to respond to tests that they had not ordered themselves, particularly if they doubted that UGRs would be appropriately actionable or beneficial to care.

\section{Limitations}

All sites were affiliated with academic medical centers, three of which are heavily invested in genomics, limiting generalizability to other health care settings where clinicians could be expected to be even less prepared to deal with UGRs. Given the small number of HCP interviews, any underlying differences in perspectives among provider types could not be assessed.

\section{Conclusion}

This study suggests that the idea of receiving UGRs in the general patient population raises important concerns for physicians with regard to utility and efficiency, patient wellbeing, and medical and ethical responsibility. Findings highlight the importance of strategic workflow integration of UGRs, including well-developed CDS. These interviews also contribute a more detailed understanding of how physicians perceive the actionability and overall significance of UGRs at the clinical level. Such insights can inform decision-making about which, when, how, and to whom genomic results are returned.

Future studies will assess HCPs' actions and impressions in response to UGRs returned through eMERGE III as these will be essential for the effective translation of genomic discoveries to patients. Additional studies in eMERGE III will focus on how UGRs affect the health behaviors, subjective well-being, and health outcomes of tested individuals.

\section{ELECTRONIC SUPPLEMENTARY MATERIAL}

The online version of this article (https://doi.org/10.1038/s41436018-0047-z) contains supplementary material, which is available to authorized users.

\section{ACKNOWLEDGEMENTS}

The authors would like to thank Josie Timmons for her contributions. This project was funded in part by several grants of the eMERGE consortium-U01HG8672 (Vanderbilt University Medical Center), U01HG8666 (Cincinnati Children's Hospital Medical Center), U01HG8679 (Geisinger), and U01HG008701 (Coordinating Center). Financial support was also provided in part by the Office of Medical Student Research at Vanderbilt University School of Medicine.

\section{DISCLOSURE}

The authors declare no conflicts of interest. 


\section{REFERENCES}

1. Green RC, Berg JS, Grody WW, et al. CORRIGENDUM: ACMG recommendations for reporting of incidental findings in clinical exome and genome sequencing. Genet Med. 2017;19:606

2. Fossey $R$, Kochan D, Winkler $E$, et al. Ethical considerations related to return of results from genomic medicine projects: the eMERGE Network (Phase III) experience. J Pers Med. 2018;8(1):2.

3. Kolor K, Duquette D, Zlot A, et al. Public awareness and use of direct-toconsumer personal genomic tests from four state population-based surveys, and implications for clinical and public health practice. Genet Med. 2012;14:860-7.

4. McGowan ML, Fishman JR, Settersten RA Jr., Lambrix MA, Juengst ET. Gatekeepers or intermediaries? The role of clinicians in commercial genomic testing. PLOS ONE. 2014;9:e108484. https://doi.org/10.1371/ journal.pone.0108484

5. van der Wouden $\mathrm{CH}$, Carere DA, Maitland-van der Zee AH, Ruffin MT 4th, Roberts JS, Green RC; Impact of Personal Genomics Study Group. Consumer perceptions of interactions with primary care providers after direct-to-consumer personal genomic testing. Ann Intern Med. 2016;164:513-22

6. Jarvik GP, Amendola LM, Berg JS, et al. Return of genomic results to research participants: the floor, the ceiling, and the choices in between. Am J Hum Genet. 2014;94:818-26.

7. Husedzinovic A, Ose D, Schickhardt C, et al. Stakeholders' perspectives on biobank-based genomic research: systematic review of the literature. Eur J Hum Genet. 2015;23:1607-14.

8. Wolf SM, Crock BN, Van Ness B, et al. Managing incidental findings and research results in genomic research involving biobanks and archived data sets. Genet Med. 2012;14:361-84.

9. Townsend A, Adam S, Birch PH, Lohn Z, Rousseau F, Friedman JM. "I want to know what's in Pandora's box": comparing stakeholder perspectives on incidental findings in clinical whole genomic sequencing. Am J Med Genet A. 2012;158A:2519-25.

10. Raghavan S, Vassy JL. Do physicians think genomic medicine will be useful for patient care? Per Med. 2014;11:424-33.

11. Mikat-Stevens NA, Larson IA, Tarini BA. Primary-care providers' perceived barriers to integration of genetics services: a systematic review of the literature. Genet Med. 2015;17:169-76.

12. Christensen KD, Vassy JL, Jamal $L$, et al. Are physicians prepared for whole genome sequencing? a qualitative analysis. Clin Genet. 2016;89:228-34.

13. Unertl KM, Field JR, Price $L$, et al. Clinician perspectives on using pharmacogenomics in clinical practice. Pers Med. 2015;12: 339-47.

14. Peterson JF, Field JR, Shi $Y$, et al. Attitudes of clinicians following largescale pharmacogenomics implementation. Pharm J. 2016;16:393-8.

15. Larson EA, Wilke RA. Integration of genomics in primary care. Am J Med. 2015;128:1251.e1251-55.

16. Gottesman 01, Kuivaniemi H, Tromp G, et al. The Electronic Medical Records and Genomics (eMERGE) Network: past, present, and future. Genet Med. 2013;15:761-71.

17. Pope $C$, Ziebland S, Mays N. Qualitative research in health care. Analyzing qualitative data. BMJ. 2000;320:114-6.

18. Gwet K. in Handbook of Inter-Rater Reliability: The Definitive Guide to Measuring the Extent of Agreement Among Raters. 3rd ed. 124 (Advanced Analytics, 2012).

19. Bollinger JM, Scott J, Dvoskin R, et al. Public preferences regarding the return of individual genetic research results: findings from a qualitative focus group study. Genet Med. 2012;14:451-7.

20. Klitzman R, Appelbaum PS, Fyer A, et al. Researchers' views on return of incidental genomic research results: qualitative and quantitative findings. Genet Med. 2013;15:888-95.
21. Tabor HK, Berkman BE, Hull SC, et al. Genomics really gets personal: how exome and whole genome sequencing challenge the ethical framework of human genetics research. Am J Med Genet A. 2011;155A:2916-24.

22. Wolf SM. Return of individual research results and incidental findings: facing the challenges of translational science. Annu Rev Genomics Hum Genet. 2013;14:557-77.

23. Bookman EB, Langehorne AA, Eckfeldt JH, et al. Reporting genetic results in research studies: summary and recommendations of an NHLBI working group. Am J Med Genet A. 2006;140:1033-40. https://doi.org/10.1002/ ajmg.a.31195

24. Biesecker LG, Mullikin JC, Facio FM, et al. The ClinSeq Project: piloting large-scale genome sequencing for research in genomic medicine. Genome Res. 2009;19:1665-74.

25. Green RC, Goddard KAB, Jarvik GP, et al. Clinical Sequencing Exploratory Research Consortium: accelerating evidence-based practice of genomic medicine. Am J Hum Genet. 2016:99:246.

26. Electronic Medical Records and Genomics (eMERGE) Network. 2018 https://www.genome.gov/27540473/electronic-medical-records-andgenomics-emerge-network/. Accessed 13 June 2018.

27. Precision Medicine Initiative (PMI) Working Group Report to the Advisory Committee to the Director, N. The Precision Medicine Initiative Cohort Program - Building a Research Foundation for 21st Century Medicine. 2015. https://acd.od.nih.gov/documents/reports/PMI_WG_report_201509-17-Final.pdf. Accessed 6 June 2018

28. Gollust SE, Gray SW, Carere DA, et al. Consumer Perspectives on Access to Direct-to-Consumer Genetic Testing: Role of Demographic Factors and the Testing Experience, Milbank Q. 2017 Jun;95(2):291-318. https://doi. org/10.1111/1468-0009.12262.

29. Burke W, Antommaria AH, Bennett R, et al. Recommendations for returning genomic incidental findings? We need to talk! Genet Med. 2013;15:854-9.

30. Middleton A, Morley KI, Bragin $\mathrm{E}$, et al. No expectation to share incidental findings in genomic research. Lancet. 2015;385(9975):1289-90.

31. Vassy JL, Christensen KD, Slashinski MJ, et al. 'Someday it will be the norm': physician perspectives on the utility of genome sequencing for patient care in the MedSeq Project. Pers Med. 2015;12:23-32.

32. Wolf SM. Return of individual research results and incidental findings: facing the challenges of translational science. Annu Rev Genomics Hum Genet. 2013;14:557-77.

33. Lazaro-Munoz G, Conley JM, Davis AM, et al. Which results to return: subjective judgments in selecting medically actionable genes. Genet Test Mol Biomarkers. 2017;21:184-94.

34. Broady KM, Ormond KE, Topol EJ, et al. Predictors of adverse psychological experiences surrounding genome-wide profiling for disease risk. J Community Genet. 2017. https://doi.org/10.1007/ s12687-017-0339-z

35. Christensen KD, Roberts JS, Royal CD, et al. Incorporating ethnicity into genetic risk assessment for Alzheimer disease: the REVEAL study experience. Genet Med. 2008;10:207-14.

36. Vassy JL, Christensen KD, Schonman EF, et al. The impact of wholegenome sequencing on the primary care and outcomes of healthy adult patients: a pilot randomized trial. Ann Intern Med. 2017:385 (9975):1289-90.

37. Bloss CS, Schork NJ, Topol EJ. Direct-to-consumer pharmacogenomic testing is associated with increased physician utilisation. J Med Genet. 2014:51:83-89.

38. Genetic Information Nondiscrimination Act. 42 USC §§ $2000 \mathrm{ff}$ et seq 122Stat. 881. 2008

39. Patient Protection and Affordable Care Act. 42 USC $\S \S 18001$ et seq. 2010.

40. Clayton EW, McGuire AL. The legal risks of returning results of genomics research. Genet Med. 2012;14:473-7. 